\title{
Nanoscale
}

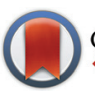

CrossMark \&lick for updates

Cite this: Nanoscale, 2016, 8, 8650

Received 19th January 2016

Accepted 18th March 2016

DOI: $10.1039 / \mathrm{c} 6 \mathrm{nr} 00468 \mathrm{~g}$

www.rsc.org/nanoscale

\section{Facile template-free synthesis of vertically aligned polypyrrole nanosheets on nickel foams for flexible all-solid-state asymmetric supercapacitors $\uparrow$}

\author{
Xiangwen Yang, ${ }^{a}$ Zhixing Lin, ${ }^{a}$ Jingxu Zheng, ${ }^{\mathrm{b}}$ Yingjuan Huang, ${ }^{\mathrm{a}}$ Bin Chen, ${ }^{\mathrm{b}}$ \\ Yiyong Mai ${ }^{* a}$ and Xinliang Feng ${ }^{a, c}$
}

\begin{abstract}
This paper reports a novel and remarkably facile approach towards vertically aligned nanosheets on threedimensional (3D) Ni foams. Conducting polypyrrole (PPy) sheets were grown on Ni foam through the volatilization of the environmentally friendly solvent from an ethanol-water solution of pyrrole (Py), followed by the polymerization of the coated Py in ammonium persulfate (APS) solution. The PPy-decorated $\mathrm{Ni}$ foams and commercial activated carbon (AC) modified Ni foams were employed as the two electrodes for the assembly of flexible all-solid-state asymmetric supercapacitors. The sheet-like structure of PPy and the macroporous feature of the $\mathrm{Ni}$ foam, which render large electrode-electrolyte interfaces, resulted in good capacitive performance of the supercapacitors. Moreover, a high energy density of ca. $14 \mathrm{Wh} \mathrm{kg}^{-1}$ and a high power density of $6.2 \mathrm{~kW} \mathrm{~kg}^{-1}$ were achieved for the all-solid-state asymmetric supercapacitors due to the wide cell voltage window.
\end{abstract}

\section{Introduction}

Electrochemical supercapacitors have emerged as one of the most important power supplies in memory backup systems, portable electronic devices, hybrid electric vehicles, etc., due to their high power delivery and long cycle-life. ${ }^{1-3}$ However, although they have high power densities, the present commercial supercapacitors have much lower energy densities $(<10$ Wh $\mathrm{kg}^{-1}$ ) than those of batteries and fuel cells, which limit their applications when high energy densities are required., ${ }^{4,5}$ Therefore, much effort has been devoted to the development of supercapacitors with improved energy density and retained high power density. In recent years, asymmetric supercapacitors, a new type of electrochemical capacitor, have drawn much attention, which employ different electrode materials with complementary working potential windows to each other. $^{6-9}$ In asymmetric supercapacitors, the working voltage can have a remarkable increase compared with their symmetri-

\footnotetext{
${ }^{a}$ School of Chemistry and Chemical Engineering, Shanghai Jiao Tong University, 800 Dongchuan RD, Shanghai 200240, P. R. China. E-mail: mai@sjtu.edu.cn ${ }^{b}$ School of Materials Science and Engineering, Shanghai Jiao Tong University, 800 Dongchuan RD, Shanghai 200240, P. R. China

${ }^{c}$ Department of Chemistry and Food Chemistry, Technische Universität Dresden, Mommsenstrasse 4, 01062 Dresden, Germany

$\dagger$ Electronic supplementary information (ESI) available: ESI figures. See DOI: 10.1039/c6nr00468g
}

cal counterparts. Thus, asymmetric supercapacitors can have significantly enhanced energy densities $(E)$, since $E$ is determined by the equation: $E=1 / 2 C_{\mathrm{s}} V^{2}$, where $C_{\mathrm{s}}$ is the specific capacitance and $V$ denotes the cell voltage. ${ }^{6-9}$

Flexible all-solid-state supercapacitors have emerged as a state-of-the-art power supply for wearable electronic devices, as they avoid a serious problem of electrolyte leaking which often occurs in traditional liquid electrolyte-based supercapacitors. ${ }^{10-13}$ Among a few recently developed electrode materials for flexible all-solid-state supercapacitors, vertically aligned two-dimensional (2D) nanosheets, such as carbon or metal oxide/sulfide nanosheets, on 3D nickel (Ni) foams have proven to show excellent electrochemical performance, owing to the large electrode-electrolyte interfaces as well as the macropores of Ni foams, which may act as a reservoir for electrolytes and thus shorten the ion diffusion distance from the exterior to the interior surfaces. ${ }^{14-18}$ Besides, the flexibility and high electrical conductivity make Ni foams ideal current collectors for flexible supercapacitors. However, the growth of vertically aligned nanosheets generally requires complex methods, including electrochemical synthesis, ${ }^{15}$ chemical vapor deposition, ${ }^{16}$ hydrothermal reduction, ${ }^{17,18}$ etc.; these approaches usually require complicated multiple steps, harsh experiment conditions, or expensive equipment. ${ }^{15-18}$ Therefore, exploration of facile approaches for the synthesis of vertically aligned nanosheets on $\mathrm{Ni}$ foams has been one of the current focuses in the development of flexible supercapacitors. 
In the present work, we demonstrate a novel and templatefree strategy for the synthesis of vertically aligned nanosheets on 3D Ni foams. Conducting polymer sheets, i.e. polypyrrole (PPy), were grown on Ni foam simply through the evaporation of the environmentally friendly solvent from an ethanol-water solution of pyrrole (Py), followed by the polymerization of the coated Py in ammonium persulfate (APS) solution. PPy was chosen because of its easy synthesis as well as high theoretical capacitance and excellent electrical conductivity for supercapacitors. ${ }^{19-21}$ The resulting PPy nanosheets possessed an average thickness of $14 \pm 2 \mathrm{~nm}$ and the average height of the PPy layer on Ni foam is $294 \pm 34 \mathrm{~nm}$. The PPy-decorated Ni foams (PPy-Ni) and commercial activated carbon (AC)-modified Ni foams (AC-Ni) were employed as the two electrodes for the assembly of all-solid-state asymmetric supercapacitors (PPy-Ni//AC-Ni), using poly(vinyl alcohol) (PVA)/ $\mathrm{LiClO}_{4}$ as the solid electrolyte. To our knowledge, this represents the first example of employing vertically aligned conducting polymer nanosheets on Ni foams for supercapacitors. The PPy-Ni//ACNi solid-state capacitor exhibited a high specific capacitance of up to $c a .40 \mathrm{~F} \mathrm{~g}^{-1}$ at $0.2 \mathrm{~A} \mathrm{~g}^{-1}$ and good cycling stability with ca. $82 \%$ capacitance retention after 2000 cycles. The two different electrode materials with complementary working potential windows rendered the asymmetric supercapacitor with a large cell voltage of $1.6 \mathrm{~V}$, a high energy density of $\mathrm{ca} .14$ Wh kg-1 and a power density of $6.2 \mathrm{~kW} \mathrm{~kg}^{-1}$. The energy and power densities are higher than those of most commercial supercapacitors $^{22,23}$ as well as those of many reported solidstate supercapacitors based on other electrode materials such as $3 \mathrm{D}$ graphene hydrogels, activated carbon/ $\mathrm{MnO}_{2}$ hybrids, graphene $/ \mathrm{MnO}_{2}$ hybrids, etc. ${ }^{24-28}$ In addition, the capacitive performance of the asymmetric supercapacitors did not apparently change with their bending. With such a good electrochemical performance, the PPy nanosheet coated Ni foams hold promise in the application as electrode materials for flexible all-solidstate asymmetric supercapacitors.

\section{Experimental section}

\section{Preparation of vertically aligned PPy nanosheets on Ni foams (PPy-Ni)}

Typically, a Py monomer (Aldrich) was dissolved in ethanolwater (v/v $2: 1$ ) mixed solvents at $0{ }^{\circ} \mathrm{C}$, forming ethanol-water solutions of Py with different concentrations of 20, 45, 65, 85 and $110 \mathrm{mg} \mathrm{mL}^{-1}$. Nickel foams (area: $1 \times 3 \mathrm{~cm}^{2}$ ) were treated by successively washing with acetone, $6 \mathrm{M} \mathrm{HCl}$ and deionized water, followed by vacuum drying at $60^{\circ} \mathrm{C}$. The pre-treated $\mathrm{Ni}$ foams were immersed into the as-prepared ethanol-water solutions of Py and then incubated for 1 hour. Subsequently, the $\mathrm{Ni}$ foams were taken out carefully and placed in the dark at room temperature for the natural volatilization of the solvent for ca. 8 hours. Afterwards, the Py-coated Ni foams were immersed into an aqueous solution of ammonium persulfate (APS, Aladdin Reagent), which contained $1 \mathrm{M} \mathrm{HCl}$. The mole ratio of APS to Py was $\sim 1$. The polymerization of Py on $\mathrm{Ni}$ foams was then carried out at $0{ }^{\circ} \mathrm{C}$ without stirring for 4 days. The final products were washed with ethanol and deionized water for over 3 cycles, followed by vacuum drying at $60{ }^{\circ} \mathrm{C}$. The loading mass of PPy on Ni foam was determined by the weight difference of the $\mathrm{Ni}$ foam before and after the PPy loading.

\section{Preparation of the $\mathrm{PVA} / \mathrm{LiClO}_{4}$ gel electrolyte}

Typically, $16 \mathrm{~g}$ PVA powder (Aladdin Reagent) was dissolved in $160 \mathrm{~mL}$ deionized water at $95^{\circ} \mathrm{C}$ under stirring. After PVA was completely dissolved, $25.6 \mathrm{~g} \mathrm{LiClO}_{4}$ (Aldrich) was added into the PVA solution and the mixture was stirred vigorously until the whole system became transparent. Then, the solution was cooled down to room temperature, yielding the $\mathrm{PVA} / \mathrm{LiClO}_{4}$ gel electrolyte.

\section{Assembly of asymmetric supercapacitors}

The as-obtained PPy-Ni samples were used directly as positive electrodes. The negative electrodes were prepared by mixing $80 \mathrm{wt} \%$ commercial powdered activated carbon, $10 \mathrm{wt} \%$ carbon black (Mitsubishi Chemicals, Inc.) and $10 \mathrm{wt} \%$ polytetrafluoroethylene (PTFE) binder, followed by coating the mixture onto Ni foams. The positive and negative electrodes were immersed into the $\mathrm{PVA} / \mathrm{LiClO}_{4}$ gel electrolyte at $60{ }^{\circ} \mathrm{C}$ for 6 hours, then taken out, cooled down to room temperature, and subsequently assembled into sandwich-like solid-state asymmetric supercapacitors. Symmetric capacitor devices were assembled following similar procedures.

\section{Characterization}

Scanning electron microscopy (SEM). SEM observations were performed using an FEI Sirion-200 (FEI Co., USA) field emission scanning electron microscope at an operating voltage of $5 \mathrm{kV}$. The Ni-PPy samples were directly placed on copper tables without other treatments.

Transmission electron microscopy (TEM). TEM studies of samples were performed using a JEM-ARM200F, equipped with a probe Cs corrector and a cold field emission gun. The accelerating voltage was $200 \mathrm{kV}$. Before the TEM measurements, Ni-PPy samples were subjected to strong sonication in ethanol for exfoliation of the active materials from the $\mathrm{Ni}$ foams. TEM samples were prepared by dropping a drop of the ethanol dispersion of the active materials onto copper grids, followed by drying at $60{ }^{\circ} \mathrm{C}$ overnight. Electron diffraction (ED) measurements were performed on the same electron microscope at an operating voltage of $120 \mathrm{kV}$.

Optical microscopy (OM). The OM observations were performed using a Leica DM4500 B optical microscope. The Ni foams coated with Py and water were directly placed on the objective table.

Electrochemical performance measurements. The performance of flexible all-solid-state supercapacitors were evaluated on an EG \& potentiostat/galvanostat Model 2273 advanced electrochemical system. PVA/LiClO 4 was used as the gel (solidstate) electrolyte for the supercapacitors. 


\section{Results and discussion}

The growth of vertically aligned PPy nanosheets on Ni foams is illustrated in Fig. 1. Typically, Ni foams were immersed in an ethanol-water (v/v 2:1) solution of Py. The complete evaporation of the mixed ethanol-water solvent at room temperature resulted in Py-coated Ni foams. Afterwards, the Py-coated Ni foams were immersed in APS solution for the polymerization of the Py monomer for 4 days, yielding the vertical PPy nanosheets on nickel foams.

The mass of the PPy nanosheets per unit area on Ni foam increased linearly with the increase in the Py concentration (Fig. 2a), indicating controllable loading of PPy by adjusting the monomer content in solution. The morphology of the asprepared PPy on Ni foam was examined by SEM (Fig. 2b-f). At the Py concentrations of $20-65 \mathrm{mg} \mathrm{mL}^{-1}$ in solution, the polymerization of Py resulted in highly interconnected films consisting of vertically aligned nanosheets on the $\mathrm{Ni}$ foam (Fig. 2b-d); the lateral dimension of the sheets increased with the increasing concentration, while their thickness did not change obviously. When the monomer concentration was higher than $65 \mathrm{mg} \mathrm{mL} \mathrm{m}^{-1}$, a large amount of spherical flowerlike nanoparticles were observed, coexisting with the nanosheets on the Ni foam (Fig. 2e and f). Herein, we describe the PPy nanosheets obtained at the Py concentration of $65 \mathrm{mg}$ $\mathrm{mL}^{-1}$ in more detail, because they show the optimum capacitor performance (to be described below). Fig. 3 presents the distinct structure of the nanosheets, the interconnection of which generates macropores that may act as a reservoir for electrolytes (Fig. 3a-c). Elemental mapping images obtained from scanning TEM (STEM) show homogeneously distributed carbon and nitrogen on the nickel foam (Fig. S1†), demonstrating the uniform coating of the PPy nanosheets. The sheets possess an average thickness of $14 \pm 2 \mathrm{~nm}$ (Fig. 3c) and an average height of $294 \pm 34 \mathrm{~nm}$ (Fig. 3d), based on statistics analysis of the dimensions of $c a .100$ nanosheets in the SEM images. The sheet-like structure was confirmed by TEM observation of the PPy exfoliated from the Ni foam by strong sonication (Fig. 3e). High-resolution TEM (HRTEM) and ED

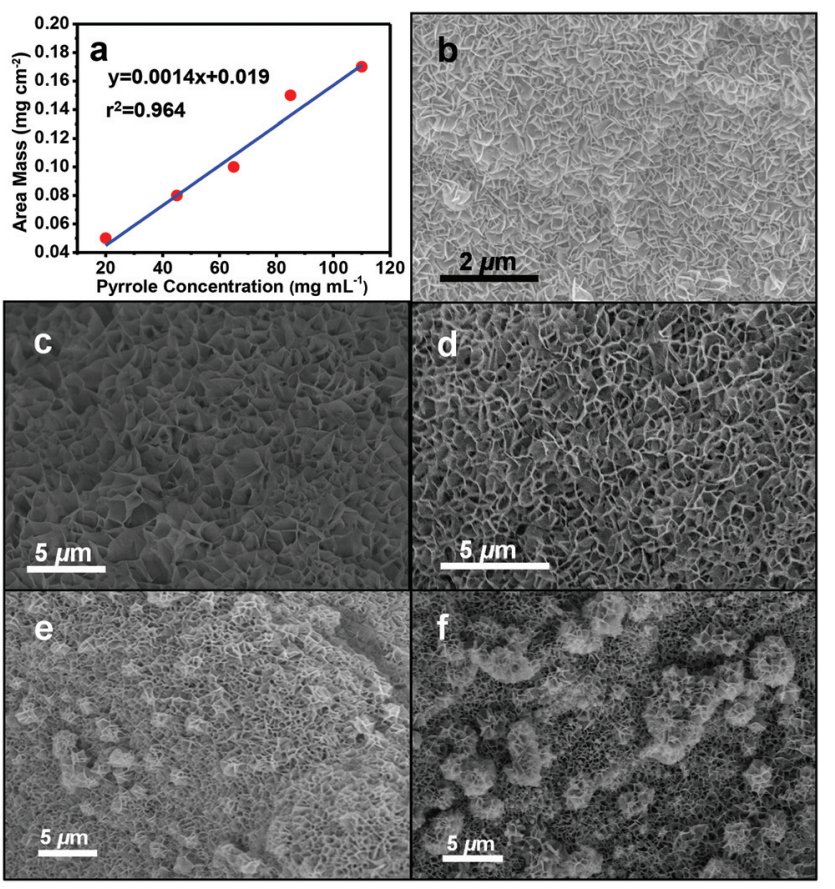

Fig. 2 (a) A linear fit of the PPy mass per unit area on Ni foam as a function of Py concentration in solution. (b-f) Typical SEM images of the PPy structures grown on $\mathrm{Ni}$ foams in ethanol-water solutions with different Py concentrations: (b) $20 \mathrm{mg} \mathrm{mL}^{-1}$; (c) $45 \mathrm{mg} \mathrm{mL}^{-1}$; (d) $65 \mathrm{mg}$ $\mathrm{mL}^{-1}$; (e) $85 \mathrm{mg} \mathrm{mL}^{-1}$; (f) $110 \mathrm{mg} \mathrm{mL}^{-1}$.
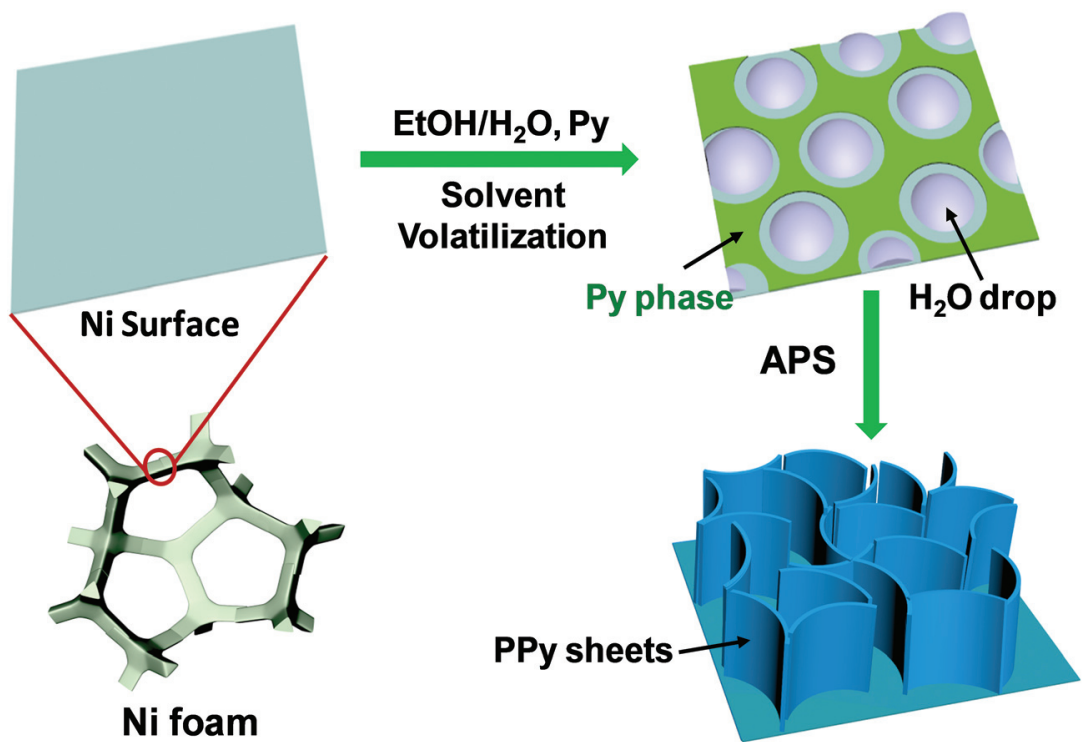

Fig. 1 Schematic illustration of the facile template-free synthesis of vertically aligned PPy nanosheets on Ni foams. 


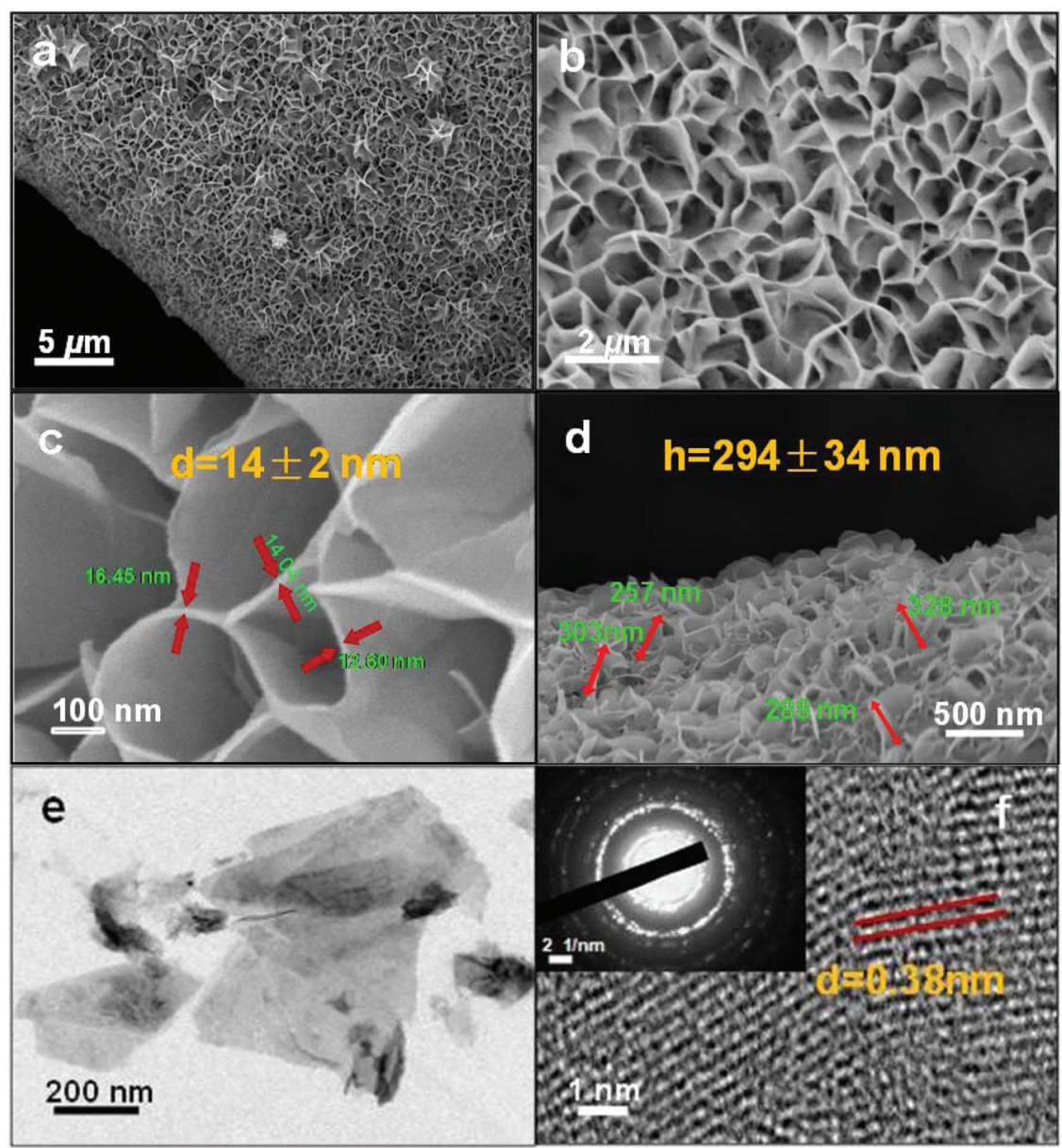

Fig. 3 Structure characterization of PPy nanosheets grown on Ni foams in the ethanol-water solution with a Py concentration of $65 \mathrm{mg} \mathrm{mL}^{-1}$. (a-d) Different magnification SEM images of the nanosheets; the thicknesses and heights of the sheets are indicated in c and d, respectively. (e) A typical TEM micrograph of the nanosheets. (f) High-resolution TEM and ED images (inset) of the nanosheets. The $0.38 \mathrm{~nm}$ distance of the crystal lattice measured for the PPy sheets is in good agreement with that $(\sim 0.39 \mathrm{~nm})$ reported in the literature. ${ }^{30}$

measurements reveal a high degree of crystallization for the PPy sheets (Fig. $3 \mathrm{f}$ and the inset), which favors the electrical conductivity of the nanosheets. ${ }^{29,30}$

A possible mechanism for the formation of vertically aligned PPy nanosheets on $\mathrm{Ni}$ foam is illustrated in Fig. 1. In the ethanol-water solution of the Py monomer, ethanol is a good solvent while water is a poor solvent for Py. At room temperature, ethanol volatilized faster than water, leaving a mixture of water and Py, which are incompatible. Thereby, before complete water evaporation, phase separation of water and Py yielded a Py film with a "sea-island" morphology on the hydrophobic surface of $\mathrm{Ni}$ foam, in which water formed the isolated "island" and Py constructed the continuous "sea" network (Fig. 1). Such a sea-island structure was observed by optical microscopy (Fig. S2a †े). Afterwards, the polymerization of Py, confined in the network domain, resulted in the growth of PPy sheets along the direction vertical to the Ni surface. Two control experiments supported this mechanism. First, without the evaporation procedure, the polymerization of Py produced spherical particles rather than vertical nanosheets on Ni foam (Fig. S2 $\mathrm{b} \uparrow$ ). Second, the polymerization of Py in the absence of $\mathrm{Ni}$ foam in ethanol-water solution yielded irregular nanoparticles instead of nanosheets (Fig. S2c $\dagger$ ).

The assembly of the PPy-Ni//AC-Ni flexible all-solid-state supercapacitor is illustrated in Fig. 4a and b; the detailed procedure is described in the Experimental section. The assembly of symmetric capacitors followed a similar procedure. AC was chosen as the counter-electrode because it is a frequently-used commercial electrode material for supercapacitors. To evaluate the voltage window of the individual $\mathrm{PPy}-\mathrm{Ni}$ or $\mathrm{AC}-\mathrm{Ni}$ electrode, $\mathrm{PPy}-\mathrm{Ni} / \mathrm{PPy}-\mathrm{Ni}$ and $\mathrm{AC}-\mathrm{Ni} / / \mathrm{AC}-\mathrm{Ni}$ symmetric capacitors were first assembled using $\mathrm{PVA} / \mathrm{LiClO}_{4}$ as the solid-state electrolyte, respectively. The galvanostatic charge/discharge and cyclic voltammetry (CV) curves measured at $0.2 \mathrm{~A} \mathrm{~g}^{-1}$ gave a voltage range of $0-0.8 \mathrm{~V}$ for the $\mathrm{PPy}-\mathrm{Ni} / / \mathrm{PPy}-\mathrm{Ni}$ supercapacitor and a potential window of $0-0.6 \mathrm{~V}$ for $\mathrm{AC}-\mathrm{Ni} / \mathrm{AC}-\mathrm{Ni}$ (Fig. 4c); within the windows the capacitors exhibited the highest capacitances under similar experimental conditions. The loading amounts of PPy and AC are also crucial for the asymmetric supercapacitor. The charge balance of two electrodes follows 


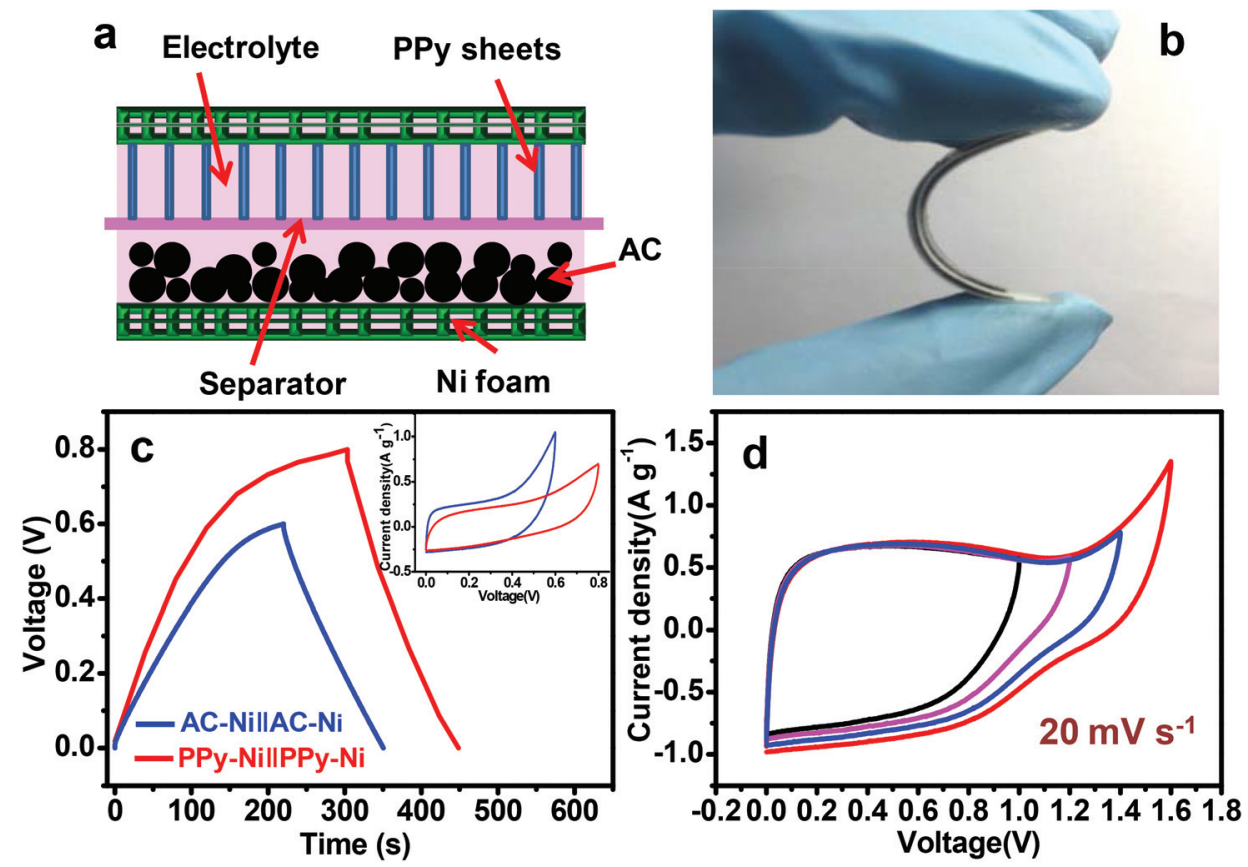

Fig. 4 (a) Schematic representation of the assembly of the PPy-Ni//AC-Ni flexible all-solid-state asymmetric supercapacitor with the PVA/LiClO 4 electrolyte. (b) A photograph of the flexible asymmetric supercapacitor. (c) Charge/discharge and CV curves of PPy-Ni//PPy-Ni and AC-Ni//AC-Ni symmetric supercapacitors with the $\mathrm{PVA} / \mathrm{LiClO}_{4}$ electrolyte. (d) $\mathrm{CV}$ curves of the optimized PPy-Ni//AC-Ni asymmetric supercapacitor measured in different potential windows.

the relationship $q^{+}=q^{-}$, which is strongly dependent on the mass of active materials in the anode and cathode. ${ }^{6}$ The mass $(m)$ balance can be decided by the equation: $m_{\mathrm{PPy}} / m_{\mathrm{AC}}=$ $\left(C_{\mathrm{AC}} / \Delta E_{\mathrm{AC}}\right) /\left(C_{\mathrm{PPy}} / \Delta E_{\mathrm{PPy}}\right)$, where $C$ and $\Delta E$ represent specific capacitances and potential windows of the two individual symmetric capacitors, respectively. ${ }^{6}$ Following this equation, $m_{\mathrm{PPy}} /$ $m_{\mathrm{AC}}$ was calculated to be $\sim 0.93$, based on the charge/discharge curves in Fig. 4c. Experimentally, the loading amount of PPy was chosen as $0.1 \mathrm{mg} \mathrm{cm}{ }^{-2}$, at which the $\mathrm{PPy}-\mathrm{Ni} / / \mathrm{PPy}-\mathrm{Ni}$ capacitor showed higher specific capacitance (Fig. S3a†). Fig. S3b $†$ shows the specific capacitances of the PPy-Ni//AC-Ni asymmetric supercapacitors with different loading ratios of PPy to AC $\left(m_{\mathrm{PPy}} / m_{\mathrm{AC}}\right)$. The sample with $m_{\mathrm{PPy}} / m_{\mathrm{AC}}=0.9$ exhibited the best performance, in good accordance with the theoretical calculations. Therefore, $0.1 \mathrm{mg} \mathrm{cm}{ }^{-2} \mathrm{PPy}-\mathrm{Ni}$ and $0.11 \mathrm{mg} \mathrm{cm}^{-2} \mathrm{AC}-\mathrm{Ni}$ were chosen to fabricate the PPy-Ni//AC$\mathrm{Ni}$ asymmetric all-solid-state supercapacitor. As the area of the employed Ni foams was $c a .1 \times 3 \mathrm{~cm}^{2}$, the loading weights of PPy and AC were $c a .0 .3$ and $0.33 \mathrm{mg}$, respectively. Fig. 2d shows the $\mathrm{CV}$ curves of the optimized PPy-Ni//AC-Ni asymmetric supercapacitor with different potential windows. The maximum voltage window can be achieved from 0 to $1.6 \mathrm{~V}$, which is much higher than those of both $\mathrm{PPy}-\mathrm{Ni} / / \mathrm{PPy}-\mathrm{Ni}$ and AC-Ni//AC-Ni symmetric capacitors. Nevertheless, when the device was operated at voltages over $1.6 \mathrm{~V}$, the current density increased rapidly and resulted in an irreversible reaction. Therefore, the potential window of $0-1.6 \mathrm{~V}$ was adopted for evaluating the electrochemical performance of the PPy-Ni//ACNi supercapacitor.
The CV curves of the PPy-Ni//AC-Ni capacitor at different scan rates of $5-100 \mathrm{mV} \mathrm{s}^{-1}$ show a quasi-rectangle shape (Fig. S4 $\dagger$ ), which are similar to the CV curves of an individual electrode and suggest good capacitive ability of the asymmetric supercapacitor. ${ }^{31}$ The capacitive performance of the supercapacitor was also studied by galvanostatic charge/discharge measurements. Typical charge/discharge curves as a function of current densities are illustrated in Fig. 5a, in which the discharge time of the capacitor decreases with the increasing current density. The specific capacitance $\left(C_{\mathrm{s}}\right)$ at different current densities is calculated on the basis of the charge/discharge curves by the formula: $C_{\mathrm{s}}=I \Delta t / \Delta V \mathrm{~m}$, where $I$ denotes the applied current; $\Delta t$ is the discharge time; $\Delta V$ represents the voltage change during the discharge; $m$ denotes the total mass of active materials (PPy and AC) of the two electrodes. ${ }^{32}$ The resulting $C_{\mathrm{s}}$ values with a maximum of $38 \mathrm{Fg}^{-1}$ at $0.2 \mathrm{~A}$ $\mathrm{g}^{-1}$ are shown in Fig. 5b. As the current density increases from 0.2 to $4.0 \mathrm{~A} \mathrm{~g}^{-1}$, the $C_{\mathrm{s}}$ slightly reduces from 38 to $21 \mathrm{~F} \mathrm{~g}^{-1}$ in the solid electrolyte, showing a good capacitance rate performance of the supercapacitor. The $C_{\mathrm{s}}$ values of the asymmetric supercapacitor are between those of the PPy-Ni//PPy-Ni and $\mathrm{AC}-\mathrm{Ni} / / \mathrm{AC}-\mathrm{Ni}$ symmetric capacitors, which are close to each other (Fig. 5b). The reason that the specific capacitance of $\mathrm{PPy}-\mathrm{Ni} / \mathrm{AC}-\mathrm{Ni}$ is slightly lower than that of $\mathrm{AC}-\mathrm{Ni} / \mathrm{AC}-\mathrm{Ni}$ is probably due to the much larger surface area of $\mathrm{AC}\left(>2000 \mathrm{~m}^{2}\right.$ $\mathrm{g}^{-1}$ ) than that of PPy, which results in more contact between the electrolyte and the active materials. As a control experiment, a symmetric supercapacitor was assembled with PPy nanosphere coated Ni foams as electrodes, which were pre- 

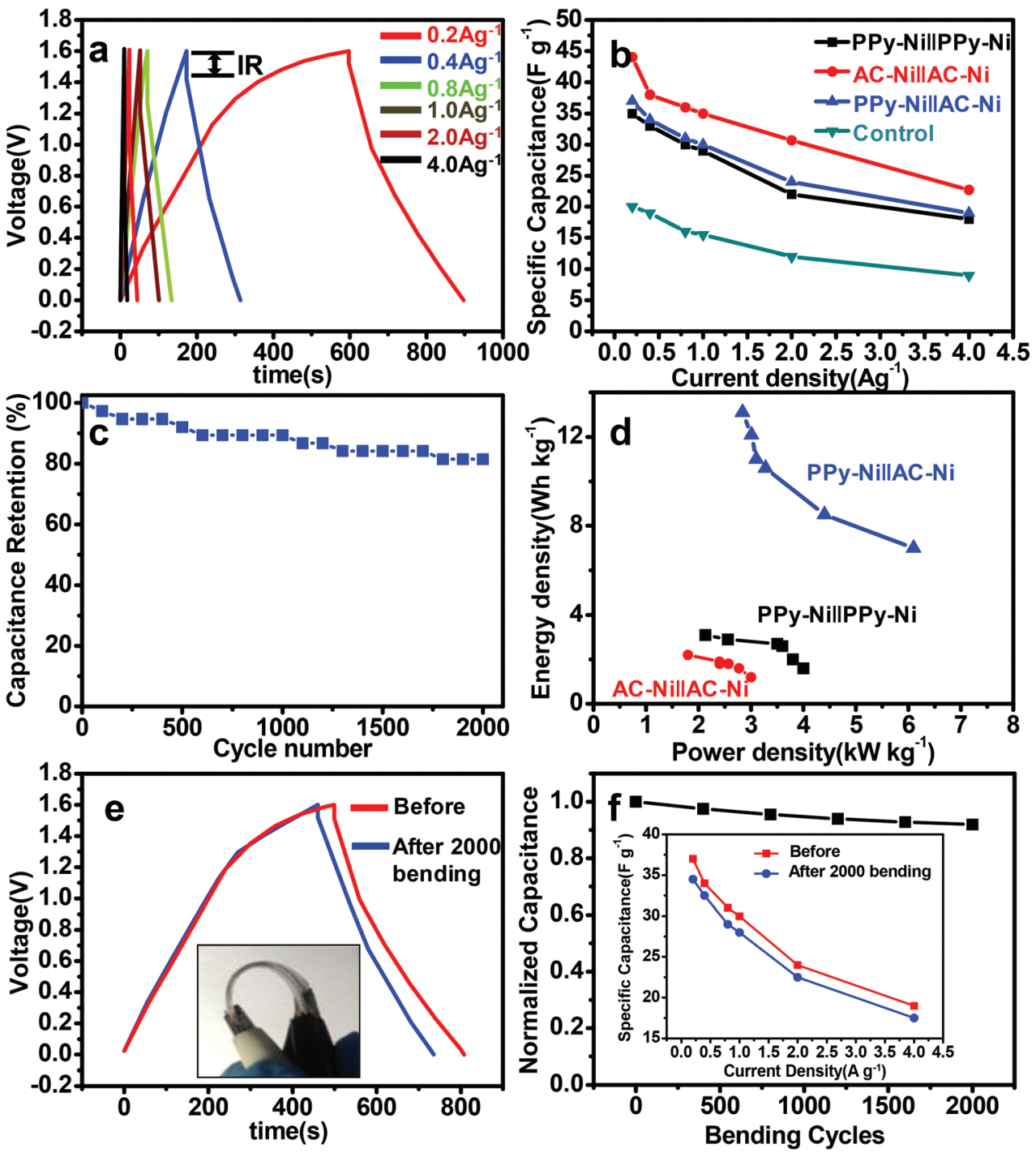

Fig. 5 (a) Charge/discharge curves of the PPy-Ni//AC-Ni all-solid-state asymmetric supercapacitor measured at different current densities. (b) Comparison of specific capacitances of the PPy-Ni//AC-Ni asymmetric supercapacitor, PPy-Ni//PPy-Ni and AC-Ni//AC-Ni symmetric supercapacitors at different current densities. The control experiment utilized the symmetric supercapacitor with PPy nanosphere coated Ni foams as electrodes, which were prepared in solution without the step of solvent volatilization. (c) Cycling stability of the asymmetric supercapacitor obtained at $1.0 \mathrm{~A} \mathrm{~g}^{-1}$. (d) Ragone plots showing the energy and power densities of the symmetric and asymmetric supercapacitors. (e) Comparison of the flexible asymmetric supercapacitor before and after 2000 bending cycles with a curvature radius of $\sim 0.8 \mathrm{~cm}$ (inset). (f) The relationship between the normalized capacitance and bending cycles; inset: comparison of the capacitance rate performance before and after 2000 bending cycles of the flexible supercapacitor.

pared in solution without the solvent volatilization step (Fig. S2b †). Its specific capacitance is much lower than that of the symmetric supercapacitor with PPy nanosheets decorated Ni foams (Fig. 5b), manifesting the advantage of vertically aligned nanosheets in the supercapacitor, which afford large electrode-electrolyte interfaces. Fig. $5 \mathrm{c}$ shows the cycling retention of the PPy-Ni//AC-Ni device at the current density of $1.0 \mathrm{~A} \mathrm{~g}^{-1}$. After 2000 cycles, $C_{\mathrm{S}}$ retained as high as $\sim 82 \%$ of the initial value, indicating a good cycling stability of the supercapacitor.

The energy density $(E)$ and power density $(P)$ of the flexible all-solid-state asymmetric supercapacitors can be calculated according to the equations: $E=1 / 2 C_{\mathrm{s}} V^{2}$ and $P=V^{2} /(4 R m)$, where $V$ is the cutoff voltage and $R=\Delta V_{\mathrm{IR}} /(2 I)$ with $\Delta V_{\mathrm{IR}}$ being the voltage drop between the first two points in the voltage drop at its top cutoff and $I$ expressing the applied current. ${ }^{33}$ For comparison, the Ragone plots of the PPy-Ni//AC-Ni asymmetric supercapacitor, PPy-Ni//PPy-Ni and AC-Ni//AC-Ni symmetric supercapacitors with the neutral solid-state electrolyte are shown in Fig. 5d. The energy and power densities of the asymmetric supercapacitor are much higher than those of the two individual symmetric counterparts. The energy density of $\sim 14 \mathrm{Wh} \mathrm{kg}^{-1}$ of the asymmetric supercapacitor at the power density of $\sim 3 \mathrm{~kW} \mathrm{~kg}^{-1}$ surpasses those of most commercial 
supercapacitors $\left(<10 \mathrm{Wh} \mathrm{kg}^{-1}\right),,^{4,5,23,34}$ as well as those of many reported all-solid-state supercapacitors with electrode materials such as 3D nitrogen and boron co-doped graphene aerogels (BN-GAs, 8.7 $\left.\mathrm{Wh} \mathrm{kg}^{-1}\right),{ }^{24}$ graphene hydrogels (0.6 Wh $\left.\mathrm{kg}^{-1}\right),{ }^{25}$ carbon nanoparticles $/ \mathrm{MnO}_{2}$ nanorods $\left(4.8 \mathrm{Wh} \mathrm{kg}^{-1}\right),{ }^{26}$ porous graphene on carbon cloth $\left(1.6 \mathrm{Wh} \mathrm{kg}^{-1}\right),{ }^{27}$ nitrogendoped pyrolyzed bacterial cellulose $\left(6.1 \mathrm{Wh} \mathrm{kg}^{-1}\right){ }^{28}$ etc. The energy density is also higher than those of many reported liquid electrolyte-based asymmetric supercapacitors, including graphene- $\mathrm{MnO}_{2} / /$ graphene $\left(10 \mathrm{Wh} \mathrm{kg}^{-1}\right),{ }^{35}$ activated carbon// mesoporous $\mathrm{MnO}_{2}$ (10.4 Wh $\left.\mathrm{Kg}^{-1}\right),{ }^{36}$ carbon nanotubes// graphene- $\mathrm{MnO}_{2}\left(12.5 \mathrm{Wh} \mathrm{kg}^{-1}\right),{ }^{37}$ etc., in which the ion transfer is much faster than in solid-state electrolytes.

Stable electrochemical performance after distortion is essential for flexible energy devices. ${ }^{38-41}$ Fig. 5e presents the comparison of the charge/discharge curves of the flexible asymmetric supercapacitor before and after 2000 bending cycles with a curvature radius of $\sim 0.8 \mathrm{~cm}$; in addition, the $\mathrm{CV}$ curves of the flexible supercapacitor before and after its bending are given in Fig. S5. $\dagger$ Fig. $5 f$ shows the relationship between the normalized capacitance and bending cycles, as well as the capacitance rate performance. Apparently, the multiple bending only slightly influenced the capacitive performance of the flexible device. The excellent retention of the capacitive performance after bending manifests great potential of the vertically aligned PPy nanosheets on Ni foams as electrode materials for flexible all-solid-state asymmetric supercapacitors.

\section{Conclusion}

In summary, this study developed a facile template-free approach for the synthesis of vertically aligned PPy nanosheets on Ni foams. The synthesis involved the evaporation of the environmentally friendly solvent from an ethanol-water solution of pyrrole (Py) on Ni foam, followed by the polymerization of the coated Py in ammonium persulfate (APS) solution. The PPy-decorated $\mathrm{Ni}$ foams and $\mathrm{AC}$ modified $\mathrm{Ni}$ foams were employed as the two electrodes for the assembly of PPy-Ni//AC$\mathrm{Ni}$ flexible all-solid-state asymmetric supercapacitors. The PPy$\mathrm{Ni} / / \mathrm{AC}-\mathrm{Ni}$ capacitor device exhibited a high specific capacitance of up to $38 \mathrm{~F} \mathrm{~g}^{-1}$ at $0.2 \mathrm{~A} \mathrm{~g}^{-1}$ and good cycling stability with $\sim 82 \%$ capacitance retention after 2000 cycles. Moreover, a high energy density of $\sim 14 \mathrm{Wh} \mathrm{kg}^{-1}$ and a power density of $6.2 \mathrm{~kW}$ $\mathrm{kg}^{-1}$ were achieved for the flexible all-solid-state supercapacitors. The approach towards vertically aligned PPy nanosheets is expected to be helpful in fabrication of vertical hybrid sheets containing metal oxides or metal hydroxides on $\mathrm{Ni}$ foams or other 3D flexible conductive porous frameworks for flexible asymmetric supercapacitors with high energy and power densities.

\section{Acknowledgements}

The authors acknowledge the financial support from the 973 Programs of China (2012CB933404 and 2013C11BA01602), the
Natural Science Foundation of China (21320102006, 21304057 and 51573091), the Research Fund for the Doctoral Program of Higher Education (20130073120088), the Natural Science Foundation of Shanghai (13ZR1421200), and the Program for Eastern Scholar in Shanghai. The authors also appreciate the Instrumental Analysis Center of Shanghai Jiao Tong University for some measurements.

\section{Notes and references}

1 Y. Zhai, Y. Dou, D. Zhao, P. F. Fulvio, R. T. Mayes and S. Dai, Adv. Mater., 2011, 23, 4828-4850.

2 L. L. Zhang and X. Zhao, Chem. Soc. Rev., 2009, 38, 25202531.

3 G. Wang, L. Zhang and J. Zhang, Chem. Soc. Rev., 2012, 41, 797-828.

4 X. Zhao, B. M. Sánchez, P. J. Dobson and P. S. Grant, Nanoscale, 2011, 3, 839-855.

5 P. Simon and Y. Gogotsi, Nat. Mater., 2008, 7, 845-854.

6 Z. Fan, J. Yan, T. Wei, L. Zhi, G. Ning, T. Li and F. Wei, Adv. Funct. Mater., 2011, 21, 2366-2375.

7 Q. Qu, Y. Shi, S. Tian, Y. Chen, Y. Wu and R. Holze, J. Power Sources, 2009, 194, 1222-1225.

8 C. Zhou, Y. Zhang, Y. Li and J. Liu, Nano Lett., 2013, 13, 2078-2085.

9 B. Zheng, T. Huang, L. Kou, X. Zhao, K. Gopalsamy and C. Gao, J. Mater. Chem. A, 2014, 2, 9736-9743.

10 Z. Niu, L. Zhang, L. Liu, B. Zhu, H. Dong and X. Chen, Adv. Mater., 2013, 25, 4035-4042.

11 C. Meng, C. Liu, L. Chen, C. Hu and S. Fan, Nano Lett., 2010, 10, 4025-4031.

12 L. Kou, T. Huang, B. Zheng, Y. Han, X. Zhao, K. Gopalsamy, H. Sun and C. Gao, Nat. Commun., 2014, 5, 3754-3763.

13 Y. Meng, Y. Zhao, C. Hu, H. Cheng, Y. Hu, Z. Zhang, G. Shi and L. Qu, Adv. Mater., 2013, 25, 2326-2331.

14 J. Zhu, K. Sakaushi, G. Clavel, M. Shalom, M. Antonietti and T.-P. Fellinger, J. Am. Chem. Soc., 2015, 137, 5480-5485.

15 C. Yuan, L. Yang, L. Hou, L. Shen, X. Zhang and X. W. D. Lou, Energy Environ. Sci., 2012, 5, 7883-7887.

16 X. Wang, Y. Wang, C. Zhao, Y. Zhao, B. Yan and W. Zheng, New J. Chem., 2012, 36, 1902-1906.

17 R. Rakhi, W. Chen, M. Hedhili, D. Cha and H. Alshareef, ACS Appl. Mater. Interfaces, 2014, 6, 4196-4206.

18 M. Huang, F. Li, J. Y. Ji, Y. X. Zhang, X. L. Zhao and X. Gao, CrystEngComm, 2014, 16, 2878-2884.

19 D. P. Dubal, S. H. Lee, J. G. Kim, W. B. Kim and C. D. Lokhande, J. Mater. Chem., 2012, 22, 3044-3052.

20 L. Yuan, B. Yao, B. Hu, K. Huo, W. Chen and J. Zhou, Energy Environ. Sci., 2013, 6, 470-476.

21 A. Davies, P. Audette, B. Farrow, F. Hassan, Z. Chen, J.-Y. Choi and A. Yu, J. Phys. Chem. C, 2011, 115, 17612-17620.

22 M. Zhi, C. Xiang, J. Li, M. Li and N. Wu, Nanoscale, 2013, 5, 72-88.

23 A. Chu and P. Braatz, J. Power Sources, 2002, 112, 236-246. 
24 Z. S. Wu, A. Winter, L. Chen, Y. Sun, A. Turchanin, X. Feng and K. Mullen, Adv. Mater., 2012, 24, 5130-5135.

25 Y. Xu, Z. Lin, X. Huang, Y. Liu, Y. Huang and X. Duan, ACS Nano, 2013, 7, 4042-4049.

26 L. Yuan, X.-H. Lu, X. Xiao, T. Zhai, J. Dai, F. Zhang, B. Hu, X. Wang, L. Gong and J. Chen, ACS Nano, 2011, 6, 656-661.

27 S. Wang, B. Pei, X. Zhao and R. A. Dryfe, Nano Energy, 2013, 2, 530-536.

28 L.-F. Chen, Z.-H. Huang, H.-W. Liang, W.-T. Yao, Z.-Y. Yu and S.-H. Yu, Energy Environ. Sci., 2013, 6, 3331-3338.

29 Y.-T. Weng, H.-A. Pan, N.-L. Wu and G. Z. Chen, J. Power Sources, 2015, 274, 1118-1125.

30 N. Nuraje, K. Su, N.-l. Yang and H. Matsui, ACS Nano, 2008, 2, 502-506.

31 X. Yang, X. Zhuang, Y. Huang, J. Jiang, H. Tian, D. Wu, F. Zhang, Y. Mai and X. Feng, Polym. Chem., 2015, 6, 10881095.

32 R. R. Salunkhe, J. Lin, V. Malgras, S. X. Dou, J. H. Kim and Y. Yamauchi, Nano Energy, 2015, 11, 211-218.
33 B. G. Choi, S.-J. Chang, H.-W. Kang, C. P. Park, H. J. Kim, W. H. Hong, S. Lee and Y. S. Huh, Nanoscale, 2012, 4, 4983-4988.

34 A. Burke, J. Power Sources, 2000, 91, 37-50.

35 T. Brousse, P.-L. Taberna, O. Crosnier, R. Dugas, P. Guillemet, Y. Scudeller, Y. Zhou, F. Favier, D. Bélanger and P. Simon, J. Power Sources, 2007, 173, 633-641.

36 Y.-T. Wang, A.-H. Lu, H.-L. Zhang and W.-C. Li, J. Phys. Chem. C, 2011, 115, 5413-5421.

37 G. Yu, L. Hu, M. Vosgueritchian, H. Wang, X. Xie, J. R. McDonough, X. Cui, Y. Cui and Z. Bao, Nano Lett., 2011, 11, 2905-2911.

38 L. Liu, Z. Niu, L. Zhang, W. Zhou, X. Chen and S. Xie, Adv. Mater., 2014, 26, 4855-4862.

39 M. F. El-Kady, V. Strong, S. Dubin and R. B. Kaner, Science, 2012, 335, 1326-1330.

40 X. Wang, B. Liu, R. Liu, Q. Wang, X. Hou, D. Chen, R. Wang and G. Shen, Angew. Chem., 2014, 126, 1880-1884.

41 D. Qi, Z. Liu, Y. Liu, W. R. Leow, B. Zhu, H. Yang, J. Yu, W. Wang, H. Wang, S. Yin and X. Chen, Adv. Mater., 2015, 27, 5559-5566. 